\title{
DÍA MUNDIAL DE LA SALUD MENTAL 2021
}

Fernando Lolas Stepke ${ }^{1}$

El lema escogido para este año recuerda que el mundo es desigual.

Especialmente, se refiere a las inequidades, que son desigualdades injustas y remediables.

América Latina es uno de los continentes más inequitativos en lo que se refiere a acceso a servicios y justa distribución de recursos.

Aunque la salud es una construcción personal, es responsabilidad de las comunidades organizadas proporcionar medios y recursos para lograrla.

\section{Las brechas}

La palabra inglesa "gap" queda bien traducida por la voz "brecha”.

La brecha 10/90 indica, en forma aproximada, que el noventa por ciento de los recursos invertidos en investigación favorece al 10 por ciento de la población.

La brecha entre saber y hacer (know/do gap) recuerda que en los países más desposeídos a menudo existe conocimiento experto que no puede aplicarse por dificultades económicas o fallas en las políticas públicas.

La llamada "brecha de tratamiento" (treatment gap), parcialmente consecuencia de la anterior, indica que personas que podrían requerir intervenciones especializadas no tienen acceso.

La brecha digital, en una etapa de instalación definitiva de la telemedicina, contribuye a perpetuar las inequidades.

Puede agregarse la brecha regulatoria, toda vez que las legislaciones en algunos países distan de estar informadas por principios científicos o avaladas por resultados concretos de la investigación.

También es posible hablar de una brecha en cuanto a los estadios evolutivos de la transición epidemiológi$c a$, con distintos niveles de alfabetización de las poblaciones, prevalencia de estigma y discriminación y carencia de apoyos en las comunidades.

\section{Los desafíos}

Es probable que no todas las brechas puedan eliminarse o atenuarse en el futuro cercano. No obstante, importa conceptualizar los desafíos que supone abordarlas. Son de diverso orden.

Puede afirmarse que la provisión de servicios requiere de personal capacitado, conocedor del estado del arte en investigación, trabajo clínico e intervenciones comunitarias.

Además, existe la necesidad de diseñar e implementar procedimientos y operaciones para que los resultados de la investigación en las áreas relevantes para la salud mental se traduzcan en acciones efectivas y eficaces (investigación traslacional).

${ }^{1}$ Profesor Titular y director del Centro Interdisciplinario de Estudios en Bioética, Universidad de Chile. Investigador, Universidad Central de Chile, Santiago, Chile. ORCID: 0000-0002-9684-2725

Correspondencia: flolas@uchile.cl 
También es esencial que se consideren los aspectos económicos y financieros de la gestión sanitaria, a menudo olvidados o ignorados al proclamar "salud para todos", sin considerar que las definiciones "aspiracionales" de salud, como la de la OMS, están incompletas si el factor "factibilidad" no se toma en cuenta.

Quizá el más importante desafío no sea técnico ni económico sino moral. Los determinantes morales de la salud guardan relación con la percepción de las personas sobre lo necesario, lo apropiado y lo justo. Engloban los llamados "determinantes socioeconómicos", que son su consecuencia.

Generalizar intervenciones o diseños probados exitosamente en grupos o comunidades requiere una conciencia generalizada de su pertinencia y la aceptación implícita o explícita de las poblaciones (scaling up de lo experimental y provisorio a lo corriente y perdurable).

\section{Las acciones}

No parece aventurado afirmar que los desafíos planteados por las brechas deben ser abordados mediante apropiadas acciones, individuales y colectivas.

El desarrollo de adecuadas tecnologías de información y gobernanza de los datos es imperativo, cautelando la privacidad y la libertad de las personas.

Paralelamente, el establecimiento de marcos referenciales consensuados y estándares de calidad en las acciones aparece como deseable.

La necesaria alfabetización de las poblaciones y la justificación ética de las decisiones debe acompañar a la fundamentación técnica y científica de las intervenciones.

Compasión, cuidado y prevención son los pilares que deben sustentar la educación profesional y fortalecer éticamente las decisiones que afectan a la salud pública. 